\title{
A "AMEAÇA COMUNISTA" NO BRASIL E A TEORIA DE MICHEL SCHOOYANS PARA A REAÇÃO DOS CATÓLICOS DO COMEÇO DOS ANOS 1960
}

\section{THE "COMMUNIST THREAT" IN BRAZIL AND MICHEL SCHOOYANS' THEORY FOR THE CATHOLIC REACTION IN THE EARLY 1960S}

\author{
Cláudio César Foltran Ulbrich ${ }^{l}$ \\ Lorena Illipronte Niwa ${ }^{2}$ \\ Luana de Oliveira Correa Treska ${ }^{3}$ \\ Luca Lima Iacomini ${ }^{4}$ \\ Matheus Kochani Frizzo ${ }^{5}$
}

Resumo: O presente artigo tem o objetivo de compreender os sentidos e significados do imaginário anticomunista e como ele se manifestou nos anos anteriores ao golpe militar de 1964, que teve como objetivo impedir uma suposta ameaça comunista. Faremos isso através da perspectiva do padre jesuíta Michel Schooyans que, em seu livro "O Comunismo e o Futuro da Igreja no Brasil", constrói uma narrativa acerca do comunismo no Brasil, baseando-se em percepções e teorias próprias, e propõe soluções para o que ele chama de "infiltração comunista".

Palavras-chave: Catolicismo, Comunismo, Anti Comunismo, Guerra Fria.

\footnotetext{
${ }^{1}$ Graduando em História (Licenciatura e Bacharelado) pela Universidade Federal do Paraná (UFPR).

${ }^{2}$ Graduanda em História (Licenciatura e Bacharelado) pela Universidade Federal do Paraná (UFPR).

${ }^{3}$ Graduando em História (Licenciatura e Bacharelado) pela Universidade Federal do Paraná (UFPR).

${ }^{4}$ Graduando em História (Licenciatura e Bacharelado) pela Universidade Federal do Paraná (UFPR).

${ }^{5}$ Graduando em História (Licenciatura e Bacharelado) pela Universidade Federal do Paraná (UFPR).
} 
Abstract: The following article has the objective of understand the senses and meanings of the anti-communist imaginary and how it manifested itself in the years before the 1964 military coup, which aimed to prevent an alleged communist menace. We will do this through the perspective of the Jesuit priest Michel Schooyans who, in his book "Communism and the Future of the Church in Brazil", builds a narrative about communism in Brazil, based on his own perceptions and theories, and proposes solutions for the what he calls "communist infiltration".

Keywords: Catholicism, Communism, Anti-communism, Cold War.

\section{Introdução}

A década de 1960 é conhecida por ser um período de efervescência política e cultural em nível mundial. O Brasil estava inserido no sistema bipolar da Guerra Fria, caracterizado pela disputa ideológica entre os Estados Unidos e a União Soviética, que buscavam hegemonia mundial de acordo com o sistema político-econômico que representavam, respectivamente, capitalismo e socialismo. No ano de 1963, o presidente João Goulart se aproximava de pautas defendidas pela esquerda, fato que chamou a atenção de setores conservadores diante de uma suposta ameaça comunista.

Diante desse contexto, o artigo propõe analisar a obra "O comunismo e o futuro da igreja no Brasil" (1963), de Michel Schooyans, teólogo e filósofo belga. Nas pouco mais de 100 páginas de seu livro, Schooyans analisa esse suposto fenômeno de infiltração comunista e propõe uma nova postura da Igreja Católica frente a essa ameaça enquanto instituição que, para ele, deve liderar a sociedade e defender seus valores. Nascido em 1930, foi professor de Filosofia Política na Pontifícia Academia de Ciências 
Sociais da Bélgica, e professor da Pontifícia Universidade Católica de São Paulo entre 1959 e $1969^{6}$, tendo sido enviado ao Brasil como parte de uma missão para conter as influências protestantes e marxistas na América Latina. A iniciativa surgiu da organização conhecida como COPAL (Faculdade de Louvain para a América Latina) ${ }^{7}$. A obra será analisada tendo em vista não apenas sua biografia, como também o contexto de produção da obra e o histórico do imaginário anticomunista no Brasil.

\section{O anticomunismo brasileiro: histórico e contextualização}

Na década de 1960, a denominada Guerra Fria atingia seu período mais crítico (MOTTA, 2000: 6). Com a Revolução Cubana em 1959, desenvolveu-se um medo generalizado nos Estados Unidos de uma ação mais incisiva da União Soviética nas Américas, o que poderia gerar não apenas uma guerra geopolítica envolvendo armas nucleares, como também a disseminação do comunismo nas nações mais pobres da América Latina, vistos como "elos frágeis" - o que levaria ao enrijecimento da chamada Doutrina Truman ${ }^{8}$. Além disso, as corridas armamentista e espacial entre EUA e URSS, bem como a intensidade propagandística, atingiram seu apogeu. Vale ainda lembrar que durante essa década aconteceriam ainda a Crise dos Mísseis, no ano de 1962 em Cuba, e a Revolução Cultural de Mao Tsé-Tung, a partir de 1966, na China.

${ }^{6}$ Disponível em: $<$ http://michel-schooyans.org/index.php?lang=fr $>$. Acesso em: 23 out. 2020.

${ }^{7}$ No original: Collège pour l'Amérique latine de Louvain. Ver: SAPPIA, 2011.

${ }^{8}$ Conjunto de práticas do governo estadunidense para contenção do comunismo nos países capitalistas mais “fracos". (MOTTA, 2000: 18-19). 
No Brasil, esse padrão político internacional bipolar se repetia. Em 1961 assumiu como presidente João Goulart (1961-1964), político filiado ao Partido Trabalhista Brasileiro (PTB). Desde os anos 1930 as correntes de esquerda vinham se organizando, surgindo a União Nacional dos Estudantes (UNE) em 1938, as Ligas Camponesas (LC) em 1945 e a Juventude Universitária Católica (JUC) ${ }^{9}$ em 1950, simpáticas a Goulart. Por outro lado, setores mais conservadores apoiados pelo bloco capitalista reagiram e se articularam, perpetrando, no fim, o famigerado golpe de 1964 contra Goulart e instaurando um regime que visava conter a suposta ameaça comunista $^{10}$.

Ao falarmos de catolicismo e marxismo, muito se pensa na Teologia da Libertação. Contudo, apesar de suas raízes anteriores, ela só surgiria como corrente interna na Igreja Católica na década de 70. Ao falarmos das décadas de 50 e 60 , devemos nos voltar para outras articulações mais modestas, mas que Lowy (1989: 7) vê como frutos de uma "evolução interna da Igreja, a partir de sua própria tradição e cultura". A partir do conceito de "afinidade eletiva", Lowy (Ibidem: 8) afirma que havia certas áreas de afinidade ou de interesse mútuo entre catolicismo e marxismo, elos que foram a base de articulações da esquerda cristã brasileira já nas décadas de 1930 e 1940, como são os casos da Juventude Escolar Católica (JEC), da Juventude Operária Católica (JOC) e da JUC, anteriormente citada, que tinham ampla base social na juventude, nas universidades e em setores do clero regular, mas estavam sob a tutela da Ação Católica Brasileira (ACB)

\footnotetext{
${ }^{9}$ Sobre a JUC, ver MATA, 1998.

${ }^{10}$ Sobre o assunto, ver: DELGADO, 2010.
} 
— movimento fundado em 1935 e controlado pela hierarquia da Igreja Católica cujo objetivo era a formação de leigos para a missão de "salvar as almas pela cristianização dos indivíduos, da família e da sociedade" (CARDOSO, 2015). A JUC, em particular, tinha uma visão que não era teológica ou sobre temas religiosos, mas de inspiração religiosa, abordando os problemas econômicos, sociais e políticos a partir de uma leitura própria do marxismo (Ibidem: 12).

Carla Simone Rodeghero busca demonstrar como o sentimento anticomunista católico se expressou no Brasil de uma forma diferente de como ocorreu nos Estados Unidos, levando em consideração que este, diferentemente do caso brasileiro, é um país que tem em seu passado - e no presente - uma forte influência do protestantismo, maior que a influência católica. Nos EUA, ser anticomunista seria uma forma de inclusão dos católicos, tanto pelos grupos conservadores quanto pelos progressistas, em um sentimento de pertencimento à nação e por oposição a um inimigo comum. No caso, esse inimigo era claramente definido através da doutrina macarthista, a partir dos anos 1950. Segundo Rodeghero (2002: 473),

(...) a pertença a uma Igreja e uma atitude abertamente favorável em relação à religião se tornaram formas de afirmar o American way of life, especialmente porque a União Soviética e seus aliados assumiram oficialmente o ateísmo. Nesse quadro, ir à igreja regularmente era um escudo contra a suspeita de subversão. Dessa forma, o que aconteceu nos anos 50 não foi um revivescimento da crença religiosa, mas sim da crença na religião, já que os benefícios da devoção não seriam místicos, metafísicos, existenciais, psicológicos ou éticos. Seriam políticos e sociais. A teologia dos anos 50 baseava-se na convicção de que a religião era símbolo da nacionalidade 
norte-americana muito mais do que na crença na existência de Deus. O caso católico é expressivo disso.

A União Soviética era vista como uma inimiga não apenas em questões econômicas, militares e geopolíticas, mas também por sua ideologia, visto que a defesa das igualdades econômica e social e a socialização dos meios de produção estavam em desacordo com a ideologia capitalista estadunidense (RODEGHERO, 2002: 468). Tais visões levaram a uma consequente marginalização da esquerda norte-americana, que tinha um espaço de debate cada vez menor. Rodeghero afirma que a imprensa católica estadunidense insistia na ênfase da perseguição do comunismo à Igreja mesmo após 1950 quando a pior parte das perseguições de regimes comunistas à Igreja já havia acabado.

No que diz respeito à história do anticomunismo no Brasil, este teria surgido antes mesmo da Guerra Fria, tomando diversas facetas ao longo do século XX. Entre 1917 e 1930, a grande preocupação da população católica com relação ao comunismo dizia respeito à ideia do laicismo, ideia amplamente repudiada em um país de maioria católica e cujo Estado era, em si, católico. Em 1921, a criação da revista A Ordem serviu como forma de propaganda anticomunista, a partir da oposição entre o cristianismo e o liberalismo e a associação do liberalismo ao comunismo ${ }^{11}$. Na década de 1930, a Liga Eleitoral Católica (LEC) passou a tomar uma atitude por meio de suas campanhas, que ressaltam:

(...) o ensino religioso facultativo, a indissolubilidade do casamento, a assistência religiosa às Forças Armadas, a

\footnotetext{
${ }^{11}$ Ver GROPPO, 2007.
} 
liberdade sindical, a defesa da propriedade, o combate a atividades subversivas. (...) a importância do voto feminino; da apresentação das propostas aos candidatos; e da publicação na imprensa da lista daqueles que haviam se comprometido com tais propostas (Ibidem: 479).

A autora menciona que a Igreja voltou a se importar com as questões trabalhistas. Nos anos 1930, tomou a preocupação de formar líderes sindicais empenhados com a Doutrina Social da Igreja ${ }^{12}$; do início dos anos 1950 ao golpe de 1964, surge uma espécie de esquerda católica que lutava contra o comunismo, marcada pela participação da Ação Católica e da Conferência Nacional de Bispos do Brasil (CNBB) em lutas sociais que diminuíssem as críticas sociais que abriam espaço para a disseminação de ideias comunistas. Na década de 1960, a Igreja percebe que devem ser tomadas ações práticas para a melhoria das condições dos trabalhadores, para que estes não cedam a "ideias subversivas". Assim, o papel central da Igreja é evidente: se voltar "à elaboração de representações sobre o inimigo e sua divulgação" (MOTTA, 2000: 67)

\section{Matrizes e imaginário anticomunistas}

Partiremos da concepção do anticomunismo como um conjunto de representações de um imaginário, essa associação um tanto paradoxal, aponta Bronislaw Baczko, entre imaginação e poder "cuja acepção corrente designava uma faculdade produtora de ilusões, sonhos e símbolos, e que pertencia sobretudo ao domínio das artes, irrompia agora num terreno

${ }^{12}$ Ensinamentos baseados na fé católica sobre "princípios éticos da fé e política". Ver: BRANDES, 2008. 
reservado as coisas 'sérias' e 'reais"” (1985: 296). Indo na contramão, portanto, de uma visão mais materialista dos fenômenos políticos, que nega ou limita a influência das ideias nas condições materiais da vida social, esse conceito recupera essa possibilidade. Nesse sentido, se reafirma que esses conceitos podem sim fazer a história, ainda que não isoladas, obviamente. Para o imaginário, portanto, estes se mostram mutuamente dependentes da realidade. Afinal, apenas se imagina algo tendo como base o real, e apenas se vivencia uma utopia na realidade.

No caso do anticomunismo, tal imaginário guia um complexo de atividades, como produção de propagandas, pregações religiosas, controles policiais, estratégias educacionais, ativismos políticos, entre outros, tendo como aspecto fundamental a oposição e o combate ao comunismo (RODEGHERO, 2002: 464). No Brasil, essa imagem geralmente esteve relacionada ao comunismo internacional, concretizado pela União Soviética, e aos movimentos estudantis e partidos políticos, como o PCB (Partido Comunista Brasileiro). Em oposição, conforme Carla Simone Rodeghero, sempre existiram "grupos com práticas anticomunistas específicas, como certos partidos políticos, a Igreja Católica, o Exército, a polícia, órgãos de imprensa, órgãos do governo federal, estadual, organizações criadas exclusivamente para o combate ao comunismo, entidades empresariais ou sindicais, etc" (2002: 465). O combate ao comunismo na América Latina também se deu, por vezes, através de ações ideológicas de assistencialismo ${ }^{13}$, como as promovidas pela Aliança Para o

${ }^{13}$ Ver. REIS, 2014. 
Progresso, ou até mesmo por intervenções nas universidades ${ }^{14}$. Esses grupos formaram imagens para representar o imaginário comunista, em que os comunistas seriam demônios, representantes do próprio inferno. Eles também seriam associados ao estrangeiro, à ilusão, à doença e à traição.

Nacionalmente, o comunismo tem raízes tão antigas quanto a Revolução Russa. O Partido Comunista Brasileiro (PCB) foi fundado em 1922, logo após os eventos da Semana de Arte Moderna de 1922. Motta aponta que o partido se tornou mais ativo durante os governos de Arthur Bernardes e Washington Luís, apoiando-se em jornais, congressos, uma liga eleitoral (MOTTA, 2000: 22-23). O PCB teve vida curta na legalidade, sendo cassado pelo congresso através da Lei Celerada de 1927, mas continuou ativo na clandestinidade, inclusive ao lado do Partido Trabalhista Brasileiro, visto que “o PTB passou de organização anticomunista nos anos 1940 a aliado do PCB nos 1960, para desagrado de muitos" (Ibidem: 35).

Segundo Motta (Ibidem: 6), o anticomunismo também tem raízes na Revolução Russa, em resposta ao "espectro comunista" que rondava a sociedade capitalista no século XX. No Brasil, seria embasado e perpetuado por diversas personalidades brasileiras - como Carlos Lacerda, líder da União Democrática Nacional, e Plínio Salgado, líder da Ação Integralista Brasileira - tendo seu apogeu após a cassação do PCB, tanto com o apoio da imprensa quanto de setores da Igreja Católica. Por fim, a fundação de organizações de esquerda entre os anos 1930 e 1950 alimentou o ímpeto de setores sociais anticomunistas (RODEGHERO, 2002: 465), com destaque para os militares, cujo imaginário anticomunista e reminiscências de

${ }^{14}$ Ver. MOTTA, 2014. 
memórias internas negativas, sobretudo relacionadas à "traição" da Intentona Comunista, em 1935 (MOTTA, 2000: 18), incentivou sua oposição ao governo supostamente "comunista" de Goulart.

O imaginário anticomunista brasileiro, historicamente, enxerga na figura de Luiz Carlos Prestes um exemplo do comunista como inimigo político e traidor da pátria. A aversão generalizada ao comunismo no Brasil propiciada principalmente pela Igreja Católica e pela imprensa leiga tornou-se terreno fértil para a formação de um imaginário negativo acerca do comunismo e dos comunistas (Ibidem: 75). Como consequência, esse imaginário penetrou no pensamento popular, confluindo com a associação do comunismo e seus adeptos ao maligno, oposto aos princípios tradicionais cristãos por provocar a depravação moral. Imaginário tal que era construído a partir de "atividades como produção de propaganda, controle e ação policial, estratégias educacionais, pregações religiosas, organização de grupos de ativistas e de manifestações públicas, atuação no Legislativo, etc" (RODEGHERO, 2002: 464). A luta contra o comunismo tomou proporção tamanha no imaginário da época que a Escola Superior de Guerra do Rio de Janeiro chegou a lançar um "Manual Básico da Escola Superior de Guerra" contendo, dentre outras coisas, uma série de estratégias a serem empregadas na guerra ideológica da luta contra o comunismo ${ }^{15}$.

A evocação dos católicos contra o comunismo e seus adeptos tinha como respaldo a ideia de que o comunismo contrariava princípios e moralidades cristãs, como em relação à permissão do aborto, do divórcio e

${ }^{15}$ Ver. DUARTE, 2014. 
da educação sexual e à equidade entre homens e mulheres, sendo, portanto, uma ameaça à família. A consequência disso foi a sua demonização, ou seja, sua associação à Satanás, que conduz ao desvirtuamento (MOTTA, 2000: 73). Outra associação estaria relacionada à perseguição da Igreja em países como a Rússia, a Espanha e o México (RODEGHERO, 2002: 464-465). Entretanto, não só a religiosidade nutria este imaginário, mas a política decorrente da Guerra Fria moldou as bases para a ideia de infiltração no país de uma ameaça exterior (MOTTA, 2000: 81). A associação a agentes patológicos e a zoomorfização dos comunistas, especialmente na figura da serpente, foram propagadas tanto pelo meio religioso quanto leigo, reforçando a ideia de uma disseminação destrutiva. De acordo com Motta, a aversão aos estrangeiros se manifestou no medo da dominação soviética, que se propagava em outros países (Ibidem: 88). Porém, um dos principais alvos do anticomunismo católico foram os judeus, associados ao comunismo por também serem vistos como uma ameaça à ordem e às tradições cristãs. É nesse cenário que se encontra o padre Michel Schooyans.

Contudo, antes de analisar sua obra, vale chamar a atenção para um questionamento levantado por Raoul Girardet, estudioso dos mitos e imaginários políticos. Para ele, não devemos reduzir o imaginário político às suas manifestações racionais ou, nesse caso, às obras teóricas. Como destaca esse autor em Mitos e mitologias políticas, existe um conteúdo passional nesse tipo de imaginário, trazido por uma espécie de dimensão onírica (1987: 9-10). Por outro lado, é inegável a importância das obras teóricas, como a de Michel Schooyans, enquanto organizadoras do 
pensamento, influenciadoras e formadoras de opinião. O que vale ter em mente dessa discussão, portanto é que existe uma dimensão coletiva do imaginário político intimamente ligada às emoções. Nesse processo, são várias as narrativas possíveis para a mobilização dessas emoções, como o medo de uma conspiração, o ódio à alguma etnia ou o desejo (ou sonho, pela terminologia do autor) de se concretizar uma utopia. Veremos que esses elementos perpassam o imaginário mobilizado pelos anticomunistas, inclusive Schooyans, com foco sobretudo na questão da "conspiração comunista" e da destruição da unidade da nação.

\section{Michel Schooyans, o comunismo e o futuro da igreja no Brasil}

Michel Schooyans (1930-) nasceu em Braine-l'Alleud, na Bélgica, sendo doutor em filosofia pelo Institut supérieur de Philosophie (1958) e em teologia pela Faculdade de Teologia de Lisboa (1978). Em 1963, quando publica sua obra O comunismo e o futuro da igreja no Brasil, era professor de Introdução à Filosofia, Epistemologia e História da Filosofia Moderna e Contemporânea na Pontifícia Universidade Católica de São Paulo. Schooyans é fortemente ligado a várias comissões do papado, atuando em muitos casos a favor da Igreja Católica ${ }^{16}$. No livro analisado, ele critica a postura dos católicos anticomunistas de seu tempo e ao mesmo

\footnotetext{
${ }^{16}$ A encíclica Mater et Magistra, do Papa João XXIII (15/05/1961), concretiza o esforço da Igreja de atualizar o seu Magistério e a reafirmar sua autoridade, sobretudo frente ao comunismo. Disponível em: http://w2.vatican.va/content/john-xxiii/pt/encyclicals/documents/hf_j-xxiii_enc_15 051961_mater.html. Acesso em: 23 out. 2020.
} 
tempo propõe uma série de contramedidas que a Igreja poderia tomar em relação ao comunismo.

A obra possui o imprimatur — isto é, a autorização eclesiástica para sua impressão - do arcebispo de São Paulo Carlos Carmelo de Vasconcelos Motta, bem como o nihil obstat — uma permissão outorgada por censor oficial da Igreja católica para publicação de obra que não contenha pensamentos ou princípios contrários à fé ou à moral católicas de Mons. José Lafayette, o que mostra que sua obra estava alinhada aos interesses da Igreja no momento. Publicado pela Editora Herder e impresso na Empresa Gráfica Carioca S/A, o livro foi criado pelo autor para ser uma obra de fácil acesso ao público leigo, ou seja, de fora da academia, pensando na difusão do mesmo em um ambiente de ebulição política e social no país. Esse seu desejo de alcançar a população ficará mais claro ao estudarmos justamente seu principal objetivo com a obra: evocar os católicos para uma reação contra o comunismo.

A fundamentação católica do discurso de Schooyans é claramente perceptível na convocação do autor para a atuação dos católicos e principalmente da instituição eclesiástica no combate ao comunismo, evocando a visão negativa dos comunistas perante a religião como justificativa para a sua contramedida. $\mathrm{O}$ autor também salienta o caráter externo atribuído ao comunismo pelos católicos de seu tempo, como algo que se infiltra e ganha espaço devido à sua facilidade em penetrar nas classes menos abastadas em razão de seu discurso materialista, mirando na 
classe média ateísta ou não praticante do catolicismo assim como no meio universitário o principal conduto da infiltração comunista ${ }^{17}$.

A exaltação à falta de moralidade dos comunistas é averiguada na afirmação de que os católicos tinham sobre eles "um conhecimento parcial da virulência de sua doutrina e do maquiavelismo de suas táticas" (SCHOOYANS, 1963: 34). O comunismo e a descristianização são, para o autor, resultantes da falta de voz ativa da Igreja, ou seja, a atuação da Igreja garantiria não somente uma frente de oposição, mas a manutenção da fé de forma a não permitir inflexões, pois "a devoção a Nossa Senhora Aparecida, quando não esclarecida, poderia perfeitamente acomodar-se a uma mística comunista, em vez de constituir um antídoto contra ela" (Ibidem: 37), sendo um verdadeiro desafio moral para a Igreja, além de uma questão de purificação do catolicismo. Desta forma, o autor coloca a ameaça comunista como um problema interno, que seria apenas influenciado por fatores externos, como o auxílio dos Estados Unidos ou da URSS, e pela expectativa de uma "infiltração comunista" e pela aversão aos países comunistas. Como Schooyans defende, o "exemplo de Cuba poderia, quando muito, apressar um processo interno já em via de desenvolvimento" (Ibidem: 21).

O anticomunismo católico também pode ser compreendido na afirmação do autor de que a resolução de questões sociais alcançaria o âmbito religioso e moral (Ibidem: 45). A voz ativa da Igreja que Schooyans

${ }^{17}$ Dada a importância das universidades para Schooyans, ele escreveu ainda mais dois artigos tratando delas: "Testemunhas da verdade" (1963) e "A reforma universitária e o desenvolvimento nacional" (1964). Disponíveis em: http://www.michel-schooyans.org/index.php?option=com_content\&view=article\&i $\mathrm{d}=29$ \&Itemid $=142 \&$ lang $=$ pt. 
conclama não se define, segundo ele, como uma atitude defensiva em relação aos comunistas, mas vendo nestes potenciais almas a serem conquistadas. Ele solicitou que os católicos abandonassem o ódio e agissem com caridade e prudência com os adversários, pois estes estariam iludidos por uma "pseudo-religião" que visa obter felicidades apenas no mundo material (Ibidem: 48-49). Desta forma, mudanças sociais devem ocorrer sob a égide cristã, não por meio de ideologias leigas, ressaltando que a atuação da Igreja nos meios sociais possui duas bandeiras, a disseminação da fé cristã e combate ao comunismo. Aliada a esse esforço deveria estar a preocupação com as classes mais baixas, mais vulneráveis às ideias comunistas - e é portanto nelas que deveriam se concentrar os esforços dos católicos, sobretudo através da educação, o que se explica pela apreensão do autor com a adesão de universitários ao movimento comunista. "Os comunistas sabem tanto quanto os católicos que o ensino superior é uma posição chave. Aliás, basta lembrar que os estudantes, também, têm a seu crédito mais de uma sublevação revolucionária, cuja inspiração comunista só escapa aos tolos" (SCHOOYANS, 1963: 89).

$\mathrm{O}$ autor, a princípio, delineia o comunismo como uma ameaça externa, concentrada, sobretudo, na União Soviética. Essa ameaça também é representada por Cuba e Fidel Castro e pelo ateísmo comunista, que atacam a liberdade tanto religiosa, quanto a material. Contudo, o perigo para Schooyans se mostra mais interno que externo, uma vez que as classes camponesa e operária são para ele mais vulneráveis à "sedução" materialista que as classes média e alta. Portanto, ele reconhece a desigualdade extrema e a corrupção das classes dirigentes, problemas 
internos da sociedade brasileira, como catalisadores da doutrina comunista. Contudo, chama a atenção ao fato de que os camponeses não teriam uma noção de classe, ou os operários nos centros urbanos, onde o processo de formação estaria mais próximo. Por isso, a tomada de consciência da miséria, indispensável ao comunismo, seria despertada pelo “desenvolvimento progressivo da indústria" (Ibidem: 24).

Nesse mesmo sentido, um "agente extrínseco" pode participar desse despertar. Esse seria não a classe dirigente, mas a "classe média de amanhã": os universitários, responsáveis pelo "quadro político, científico e cultural do Brasil de amanhã", que podem ser seduzidos pela mística comunista e se tornarem de fato "a principal ameaça comunista" (Idem). Schooyans admite que o marxismo se mostra como uma das várias interpretações possíveis do Brasil da época, percebendo que muitos dos atuais pensadores brasileiros mais atentos à realidade nacional são de inspiração marxista mais ou menos pronunciada, pois os pensadores católicos e sociólogos positivistas não foram capazes de também elaborar uma mística. Porém, ainda o associa à alienação da liberdade e ao ateísmo $^{18}$.

\footnotetext{
18 “Aos católicos apraz frisar o caráter militante dêste (SIC) ateísmo: o comunismo persegue a Igreja, os padres, os católicos em geral. Limita a liberdade de culto. Expropria os bens da Igreja. Seculariza as instituições de ensino. Laiciza as obras de assistência. Numa palavra, impede os católicos de viverem a sua religião". (SCHOOYANS, 1963: 13)
} 


\section{Catolicismo e Comunismo: uma compatibilidade possível?}

Conforme anteriormente citado, a pequena afinidade existente entre o catolicismo e o cristianismo abre caminho para a formação de movimentos de esquerda católicos. Nesse sentido, haveria uma compatibilidade mínima entre o catolicismo e o comunismo, o que é reprovado por Schooyans, que defende haver em sua época uma vertente católica mais esclarecida cujos métodos por vezes "flertam" com os dos comunistas. Assim, para ele, "não é menos verdade que as suas atividades parecem inspirar-se em motivos oportunistas, ditados mais por preocupações táticas do que doutrinais" (Ibidem: 18). Essa redução do comunismo à máxima "o fim justifica os meios" está aliada ao medo de Cuba/Fidel e do ateísmo comunista, que atacariam a liberdade tanto religiosa quanto da propriedade privada. Assim, o comunismo seria capaz apenas de se confundir ou de se utilizar de resíduos do catolicismo, desprovidos de conteúdo teológico (Ibidem: 30-31). Isso explicaria o seu sucesso tanto entre os pobres quanto entre a elite intelectual, que caminhariam lado a lado na "falta de escrúpulos morais", sendo a sua religião a "do dinheiro e dos prazeres" (Ibidem: 61).

Em um sentido mais teórico, Schooyans entende que o uso apenas de considerações teológicas, ou seja, não filosóficas ou de outro tipo, implica na ininteligibilidade entre o fiel católico e o ateu que se pretende converter (Ibidem: 14), sobretudo se comunista. Para o autor, a superação desse problema intrínseco à comunicação, intensificado pela forma como o comunismo enxerga a religião, não deve nem pode ser superado pela iniciativa comunista, mas sim apenas pela Igreja, que para isso deve voltar 
a tratar dos problemas sociais mais elementares. Porém, devemos salientar que essa superação, todavia, não implicaria em uma relação de compatibilidade ou diálogo entre os dois lados, o que Lowy entende como possível, mas sim em uma vitória do projeto político-teológico católico. $\mathrm{Ou}$ seja, Schooyans coloca como única saída a sobreposição da religião sobre o comunismo, para ele absolutamente ateu, ou mesmo anticristão. Como ele mesmo destaca, "a ignorância crassa de alguns católicos que se põem a condenar o comunismo, sem antes ter adquirido um mínimo de conhecimentos precisos sobre o assunto, conhecimentos esses absolutamente indispensáveis para escapar ao ridículo!" (p. 17). Esse pensamento vai ao encontro daquele dos militares, como aqueles responsáveis pelo Manual Básico da Escola Superior de Guerra, que julgavam necessário se ter um conhecimento mínimo a fim de se combater os comunistas de maneira realmente efetiva.

Podemos entender que essa sua oposição ao materialismo histórico da doutrina comunista se deve à tradição anti materialista na qual Schooyans se baseia, renovada com a promulgação da Encíclica Divini Redemptoris de Pio XI em 1937. Nela, o papa trata sobre o comunismo ateu, condenando-o por ser, pelo que defende, intrinsecamente mau. Mas mais que isso, recomenda qual deveria ser a atitude da Igreja perante o comunismo, chamando a atenção para os aspectos que julga mais sórdidos de sua doutrina, difusão e consequências e enfatizando, em seguida, a oposição que deve fazer a doutrina da Igreja. Dentre suas características, elencadas na Divini Redemptoris, há justamente o desapego dos bens terrenos. Como outros documentos religiosos, as encíclicas são dirigidas 
especificamente ao mundo católico. Esta encíclica, especificamente, funcionou como um apelo aos católicos de todas as classes, a fim de estimular uma reação destes através da obra social da Igreja, tal como Schooyans esperava.

\section{Conclusões}

Schooyans aborda o medo de Cuba/Fidel, cuja revolução ateia ainda assombrava os anticomunistas católicos. Porém, se o maior medo dos militares anticomunistas leigos são os militares traidores, herdeiros da Intentona Comunista, o de Schooyans são os jovens e universitários. Movimentos como a JEC, a JOC e a JUC — além da própria Ação Católica - já tinham, respectivamente, 22, 35 e 12 anos, demonstrando a força política dos jovens comunistas ou, na visão de Schooyans, a sua suscetibilidade a serem "enfeitiçados" pelo comunismo. Para o jesuíta, isso se deve à sua formação presumidamente falha, que levaria à "falta de legítima ambição pessoal, bem como de espírito crítico" (SCHOOYANS, 1963: 28) e, consequentemente, ao refúgio no comunismo e na alienação da liberdade em favor de seus dirigentes.

Dessa forma, Schooyans vê na juventude, sobretudo a das universidades, para ele o ponto nevrálgico na luta contra o comunismo e, portanto, o espaço mais suscetível a uma "ameaça comunista". Primeiramente por ela constituir a futura elite intelectual, o que já é motivo de preocupação para ele - que tem em vista intelectuais comunistas de sua época, como Caio Prado Júnior, por exemplo (Ibidem: 26). Mas também por essa juventude ter um forte senso de classe, o que abriria a 
possibilidade de uma luta de classes (Ibidem: 29) e, consequentemente, uma ruptura social irreparável - lembrando a influência do ideal romântico no anticomunismo, sobretudo no sentido de uma nação organicamente organizada, ou seja, que como um corpo humano, não deveria sofrer problemas internos para funcionar corretamente (MOTTA, 2000: 50).

A carreira acadêmica e político-religiosa de Schooyans, passando por áreas da Filosofia e da Teologia até sua atuação junto ao Papado, transparecem na obra analisada. Ele não apenas procura se distanciar de correntes anticomunistas "radicais" como preza, sobretudo, pela racionalidade ao elaborar seu conjunto de medidas de combate ao comunismo. Contudo, ao mesmo tempo em que ele procura se colocar como um analista objetivo da efervescência anticomunista que presencia no interior da Igreja, procurando categorizar, criticar e unificar as diversas correntes, Schooyans ainda faz parte de seu tempo. Por mais que tente ser equilibrado durante a obra, compartilha de um imaginário que se formou durante anos, reunindo medos e estereótipos, têm influência em sua análise, assim como acontecimentos políticos a nível mundial e nacional dos quais foi contemporâneo. Não por coincidência escreve um ano antes do golpe militar de 1964, um período politicamente conturbado e que trouxe à tona um longo histórico de tensões. Vale lembrar, nesse contexto, a atuação da vertente "Tradição, Família e Propriedade" da Igreja Católica no golpe através da conhecida "Marcha da Família com Deus pela Liberdade" (OLIVEIRA; NEVES JÚNIOR. 2014). Ou seja, praticamente liderando 
esse movimento político civil conservador, os católicos tentavam frear o avanço do comunismo no Brasil.

\section{Referências}

\section{Fontes}

SCHOOYANS, M. O comunismo e o futuro da igreja no Brasil. São Paulo: Editora Herder, 1963.102 p. Disponível em: $<$ https://ia802506.us.archive.org/5/items/ocomunismoeofutu00scho/ocomu nismoeofutu00scho.pdf>. Acesso em: 23 out. 2020.

\section{Bibliografia}

BACZKO, Bronislaw. "A imaginação social”. In: LEACH, Edmund et Al. Anthropos-Homem. Lisboa, Imprensa Nacional/Casa da Moeda, 1985.

DELGADO, Lucília de Almeida Neves. O governo João Goulart e o golpe de 1964: memória, história e historiografia. Tempo, Niterói, v. 28, p. 123-144, 2010.

DUARTE, Luiz Claudio. Os intelectuais da Escola Superior de Guerra e a vitória do Ocidente: do júbilo ao desconforto. Cadernos de História, v. 15, n. 22, p. 114-134, 2014.

GIRARDET, Raoul. Mitos e mitologias politicas. São Paulo: Companhia das Letras, 1987.

GROPPO, Célia Maria. Ordem no céu, ordem na terra: a revista A Ordem e o ideário anticomunista das elites católicas (1930-1937). São Paulo: PUC-SP, 2007. Dissertação (Mestrado em História).

LOWY, Michael. Marxismo e cristianismo na América Latina. Lua Nova, São Paulo, n. 19, p. 05-22, Nov. 1989.

MATA, Sérgio da. JUC e MMC: polaridade político-religiosa em Belo Horizonte. Revista de História Regional, Ponta Grossa, p. 65-86, 1998. 
MOTTA, Rodrigo Patto Sá. Em guarda contra o "perigo vermelho": o anticomunismo no Brasil (1917-1964). São Paulo, 2000. 368 p. Tese (Doutorado em História Econômica) - Faculdade de Filosofia, Letras e Ciências Humanas, Universidade Federal de São Paulo, São Paulo.

MOTTA, Rodrigo Patto Sá. As universidades e o regime militar: cultura política brasileira e modernização autoritária. Rio de Janeiro: Zahar, 2014.

OLIVEIRA, Ana Claudia Rodrigues de; NEVES JUNIOR, José Wilson Assis. Reedição da "Marcha da Família com Deus pela Liberdade" 50 anos depois do golpe de 1964: manifestações anacrônicas em favor da ditadura militar no Brasil. SEMANA DE CIÊNCIAS SOCIAIS: 50 ANOS DEPOIS DO GOLPE MILITAR, $X X V$, Londrina, 8 a 10 de abril de 2014. Anais... Londrina: Universidade Estadual de Londrina, 2014.

REIS, Daniel Aarão. Ditadura e democracia no Brasil: do golpe de 1964 à Constituição de 1988. São Paulo: Editora Schwarcz/Companhia das Letras, 2014.

RODEGHERO, Carla Simone. Religião e patriotismo: o anticomunismo católico nos Estados Unidos e no Brasil nos anos da Guerra Fria. Revista Brasileira de História, São Paulo, v. 22, n. 44, p. 463-488, 2002.

SAPPIA, Caroline. De "l'angoisse" à l'œcuménisme: La perception catholique du protestantisme en Amérique latine. In: Social Compass: international review of sociology of religion, Vol. 58, no.2, 2011. p. 203-213.

\section{Webgrafia}

BRANDES, Dom Orlando. A Doutrina Social da Igreja e a Política. CNBB. 05 set. 2008. Disponível em: $<$ http://www.cnbb.org.br/a-doutrina-social-da-igreja-e-a-politica/>. Acesso em: 23 out. 2020.

CARDOSO, Nathalia. Dom Helder Câmara, um Servo de Deus. Arquidiocese do Rio de Janeiro. 24 jul. 2015. Disponível em: $<$ http://arqrio.org/noticias/detalhes/3399/dom-helder-camara-um-servo-dedeus $>$. Acesso em: 23 out. 2020. 
Cadernos de Clio, Curitiba, v. 10, nº 1, 2019

Recebido em: 03/08/2019

Aprovado em: 06/11/2020 